\title{
Otimização das condições de obtenção de biodiesel de óleo de soja utilizando o delineamento experimental de mistura
}

\section{Conditions optimization for obtaining biodiesel from soybean oil using the mixture experimental design}

\author{
Dionisio Borsato ${ }^{1 *}$; Carmen Luisa Barbosa Guedes²; Ivanira Moreira3; Jurandir \\ Pereira Pinto ${ }^{3}$; Gabriel Henrique Dias ${ }^{4}$; Kelly Roberta Spacino.
}

\section{Resumo}

A otimização do rendimento da reação de transesterificação de obtenção do biodiesel B100 foi estudada utilizando hidróxido de sódio, hidróxido de potássio, metóxido e etóxido de sódio como catalisadores. Foi aplicado o delineamento experimental de mistura simplex centróide e os resultados da otimização indicaram, com metanol, um rendimento de $97,61 \%$ quando se usa $30,77 \%$ de $\mathrm{NaOH}$ e $69,23 \%$ de metóxido de sódio e, com etanol, um rendimento de $89,32 \%$ quando se usa apenas o etóxido de sódio. A análise cromatográfica indicou que o biodiesel B100 obtido encontra-se dentro dos parâmetros estabelecidos pela Legislação Brasileira.

Palavras-chave: Biodiesel. Transesterificação. Delineamento de mistura.

\begin{abstract}
The optimization of the yield of transesterification reaction to obtain the B100 biodiesel has been studied using sodium hydroxide, potassium hydroxide, methoxide and sodium ethoxide as catalysts. We applied a randomized simplex centroid mixture and the results of optimization indicate, when using methanol, a yield of $97.61 \%$ when using $30,77 \% \mathrm{NaOH}$ and $69,23 \%$ of sodium methoxide and a yield of $89,32 \%$ when using only the sodium ethoxide whit ethanol. Chromatographic analysis indicated that the B100 biodiesel obtained is within the parameters established by Brazilian Legislation.
\end{abstract}

Key-words: Biodiesel. Transesterification. Design of mixture.

\footnotetext{
1Professor Associado do Departamento de Química da Universidade Estadual de Londrina. dborsato@uel.br ${ }^{2}$ Professora Adjunto do Departamento de Química da Universidade Estadual de Londrina. ${ }^{3}$ Doutorandos do Programa de Pós-graduação em Química da Universidade Estadual de Londrina. ${ }^{4}$ Mestrando do Programa de Pós-graduação em Bioenergia da Universidade Estadual de Londrina ${ }^{5}$ Aluna de Graduação do Curso de Licenciatura em Química da Universidade Estadual de Londrina ${ }^{*}$ Autor para correspondência
} 


\section{Introdução}

O Brasil é um País de destaque no cenário mundial de biocombustíveis. Na década de 70, foi implementado o Programa Nacional do Álcool para abastecer com etanol, de forma extensiva, veículos movidos normalmente a gasolina. Pela sua extensão territorial, associada as excelentes condições climáticas, é considerado um paraíso para a produção de biomassa para fins alimentares, químicos e energéticos (HOLANDA, 2004).

As matérias-primas e os processos para a produção de biodiesel dependem da região considerada. As diversidades sociais, econômicas e ambientais geram distintas motivações regionais para a sua produção e consumo. Comparado ao óleo diesel derivado do petróleo, o biodiesel pode reduzir em $78 \%$ as emissões líquidas de gás carbônico, considerandose a reabsorção pelas plantas. Além disso, reduz em $90 \%$ as emissões de fumaça e praticamente elimina as emissões de óxidos de enxofre e pode ser usado em qualquer motor de ciclo diesel, com pouca ou nenhuma necessidade de adaptação (HOLANDA, 2004).

O biodiesel pode ser obtido, de forma viável, a partir do craqueamento térmico, microemulsificação ou por reações de transesterificações dos óleos vegetais. $\mathrm{O}$ craqueamento térmico ou pirólise é a conversão de uma substância em outra por meio do uso de energia térmica, na ausência do oxigênio, a temperaturas superiores a $450^{\circ} \mathrm{C}$ (FUKUDA; KONDO; NODA, 2001). Em algumas situações, esse processo é auxiliado por um catalisador para a quebra das ligações químicas, de modo a gerar moléculas menores. $\mathrm{O}$ uso da técnica de microemulsificação com solventes tem sido estudado para resolver os problemas relacionados com a alta viscosidade dos óleos vegetais (DANTAS; SILVA; NETO, 2001). A transesterificação ou alcoólise consiste na reação entre a mistura de um triglicerídeo com um álcool, na presença de catalisador, para formar ésteres e um subproduto, o glicerol (FUKUDA; KODO; NODA, 2001).
Dentre os álcoois empregados na transesterificação de óleos e gorduras, os mais utilizados são o metanol e o etanol. O metanol é mais amplamente empregado na produção de biodiesel e, por ser mais reativo, implica em menor temperatura e tempo de reação (LÔBO; FERREIRA; CRUZ, 2009).

$\mathrm{O}$ desenvolvimento de qualquer produto envolvendo mais de um ingrediente requer algumas formas particulares de experimentos para a mistura (THONSON, 1981). Delineamentos para mistura são empregados em vários experimentos para o desenvolvimento de produtos. Nestes ensaios, dois ou mais ingredientes ou componentes são misturados em várias proporções e as características dos produtos resultantes são registradas. As respostas dependem, somente, das proporções dos componentes presentes na mistura e não da quantidade absoluta na mistura (CORNELL, 1990).

Uma dificuldade encontrada em muitos experimentos para mistura é que alguns dos componentes estão sujeitos a limites superior e/ ou inferior. Tais limites podem produzir regiões do delineamento com formas diferenciadas para a qual é impossível utilizar alguns delineamentos. Mclean e Anderson (1966) propuseram uma solução para este problema através da realização dos experimentos em pontos extremos e vários centróides na região de restrição do delineamento. Esses procedimentos são conhecidos como delineamentos de vértices extremos e, como os delineamentos de Scheffé (STEINBERG; HUNTER, 1984), permitem explorar toda a região experimental.

Portanto, a formulação ótima de um produto não é estritamente um problema tecnológico, tão pouco um problema comercial, somente. Em geral, ambas as áreas oferecem restrições que contribuem para determinar quais formulações são possíveis (GACULA, 1993). Para fazer um bom uso dos métodos de otimização é necessário que os resultados sejam utilizados como um ponto de partida para a tomada de decisão. Os métodos de otimização têm sido aplicados de maneira variada na indústria de 
processos químicos, térmicos e gerenciamento para redução de custos (ARTEAGA et al., 1994).

Em relação à obtenção de formulações ótimas, os delineamentos de mistura, podem gerar várias respostas simultaneamente o que pode dificultar a busca da solução ótima (CHEN; LEE; CRAPO, 1993; ARTEAGA, et al., 1994).

Derringer e Suich (1980) sugeriram um método para determinar a melhor combinação de múltiplas respostas com restrições. O método necessita de uma nova função objetivo. Eles sugeriram uma função compromisso, que define os intervalos desejáveis. Essa abordagem é considerada um método de programação não linear para uma solução ótima a partir de uma combinação simultânea de modelos com restrições.

O presente trabalho teve como objetivo apresentar uma análise detalhada das condições de obtenção do biodiesel, a partir da reação de transesterificação com metanol e etanol, examinando a influência de diferentes tipos de catalisadores no rendimento da reação empregando um delineamento de mistura.

\section{Materiais e métodos}

\section{Reação de transesterificação}

A reação de transesterificação dos triglicerídeos do óleo de soja refinado $(100 \mathrm{~mL})$ foi efetuada com metanol e etanol absoluto, grau analítico, com catalisador alcalino sob aquecimento, a 60 e $70^{\circ} \mathrm{C}$, respectivamente, e agitação lenta.

\section{Catalisador}

Foram utilizados como catalisadores hidróxido de potássio, hidróxido de sódio, metóxido e etóxido de sódio, grau analítico, cujas quantidades estabelecidas pelo delineamento de mistura, foram adicionados diretamente no álcool metílico e álcool etílico na concentração de $0,8 \mathrm{~g} / 50 \mathrm{~mL}$ de álcool.

\section{Separação das fases}

As fases foram separadas em um funil de separação de $250 \mathrm{~mL}$.

\section{Purificação do biodiesel}

Para promover a separação do glicerol, triglicerídeos e os álcoois presentes os ésteres obtidos foram lavados com água, à $80^{\circ} \mathrm{C}$, contendo $1,5 \%$ de ácido acético glacial e lavados com água, à $80^{\circ} \mathrm{C}$, até $\mathrm{pH}$ neutro e desumidificados em estufa $140^{\circ} \mathrm{C}$ por 2 horas.

\section{Rendimento}

O rendimento foi calculado de acordo como a reação de transesterificação, a massa do biodiesel obtido e a massa de óleo de soja utilizada tendo como base o ácido oleico.

\section{Delineamento experimental para mistura (STATISTICA, 2009).}

Foi utilizado um planejamento simplex-centróide (Figura 1), com $2^{\mathrm{q}}-1$ combinações de misturas onde q é o número de componentes ou variáveis cuja soma é 1 ou $100 \%$, para 3 componentes com duas repetições no ponto central (CALADO; MONTGOMERY, 2003).

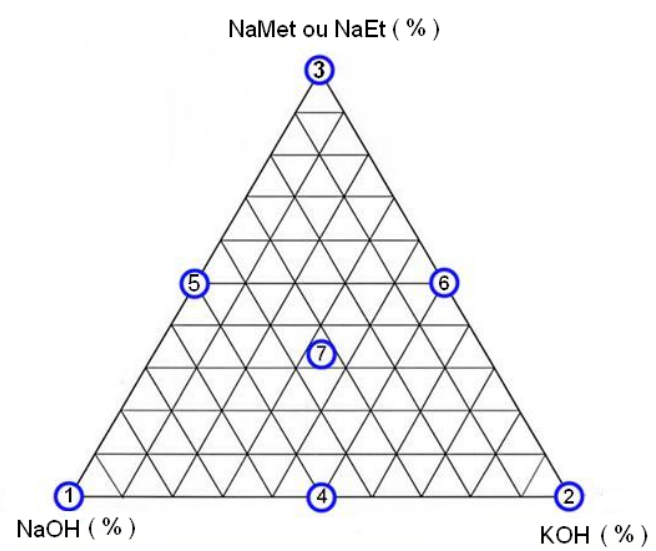

Figura 1. Delineamento experimental simplex centróide para 3 componentes. 


\section{Modelo Matemático}

A função utilizada foi do tipo

$$
Y(\mathrm{x}, \mathrm{z})=\sum_{1 \leq i \leq q} \gamma_{i}^{\circ} \mathrm{x}_{i}+\sum_{1 \leq i \leq j \leq q} \gamma_{i j}^{\circ} \mathrm{x}_{i} \mathrm{x}_{j}+\gamma_{123}^{\circ} \mathrm{x}_{1} \mathrm{x}_{2} \mathrm{x}_{3}
$$

Onde, $\mathrm{Y}$ representa a função resposta dos dados experimentais; $x_{1}, x_{2}$ e $x_{3}$ são as variáveis independentes e correspondem a porcentagem de $\mathrm{NaOH}, \mathrm{KOH}$ e metóxido de sódio ou etóxido de sódio, na mistura, respectivamente, $\mathrm{z}$ é a variável agente de transesterificação que foi codificada para $\mathrm{z}=+1$ para a presença de metanol e $\mathrm{z}=-1$ que representa a presença de etanol na reação e $\gamma$ os parâmetros estimados (CORNELL, 1990)

\section{Análise cromatográfica}

Foi utilizado um cromatógrafo modelo GC17A com detector de ionização de chama Marca Shimadzu, com uma coluna DB1 (J\&W Scientific) $100 \%$ polimetilsiloxano com $30 \mathrm{~m}$ de comprimento x $0,25 \mathrm{~mm}$ de diâmetro interno $\mathrm{x} 0,25 \mathrm{~mm}$ de espessura de filme. A temperatura do Injetor Split foi de $340^{\circ} \mathrm{C}$ e a temperatura do detector de $340^{\circ} \mathrm{C}$. A rampa de aquecimento da coluna foi mantida inicialmente à temperatura de $50^{\circ} \mathrm{C}$ por 2 minutos e, após isso, aquecida na razão de $10{ }^{\circ} \mathrm{C} / \mathrm{min}$ até $180^{\circ} \mathrm{C}$ permanecendo nessa temperatura por 2 minutos, a seguir, aquecida a razão de $15^{\circ} \mathrm{C} / \mathrm{min}$ até $340^{\circ} \mathrm{C}$ permanecendo nessa temperatura por 10 minutos. A vazão do gás de arraste, $\mathrm{N}_{2}$, foi de $1,5 \mathrm{~mL} / \mathrm{min}$ e o volume de injeção de $2,0 \mathrm{~mL}$ com razão de split 10. Os dados foram coletados por meio do Software CLASS-CR10 Shimadzu.

\section{Resultados e discussão}

Transesterificação com metanol

A reação de transesterificação foi conduzida, com os catalisadores previamente dissolvidos no álcool metílico, utilizando metanol em excesso para deslocar a reação no sentido de formação dobiodiesel. Após a separação da glicerina o biodiesel obtido foi lavado com água acidificada e desumidificado em estufa. Em seguida foi determinado o rendimento da reação.

A Tabela 1 mostra o delineamento simplexcentróide utilizado bem como os valores médios experimentais dos rendimentos obtidos em triplicata, com os diferentes catalisadores quando se utilizou o metanol como reagente de transesterificação.

Tabela 1 - Delineamento experimental e o rendimento obtido quando se utilizou o metanol.

\begin{tabular}{ccccclll}
\hline $\begin{array}{c}\text { Delineamento } \\
*\end{array}$ & $(1 ; 0 ; 0)$ & $(0 ; 1 ; 0)$ & $(0 ; 0 ; 1)$ & $(1 / 2 ; 1 / 2 ; 0)$ & $(1 / 2 ; 0 ; 1 / 2)$ & $(0 ; 1 / 2 ; 1 / 2)$ & $(1 / 3 ; 1 / 3 ; 1 / 3)$ \\
$\begin{array}{c}\text { Rendimento } \\
(\%)\end{array}$ & 96,78 & 96,14 & 97,30 & 96,70 & 97,58 & 96,89 & 97,07 \\
\hline
\end{tabular}

$*(\% \mathrm{NaOH}, \% \mathrm{KOH}, \% \mathrm{NaMet})$ 
O domínio experimental consistiu de diferentes proporções dos catalisadores utilizados, variando de 0 a $100 \%$ sendo $x_{1}$ representado pelo hidróxido de sódio, $\mathrm{x}_{2}$ pelo hidróxido de potássio e $\mathrm{x}_{3}$ pelo metóxido de sódio. A equação canônica (1), ajustada aos dados experimentais, onde Y1 representa o rendimento da reação quando se utilizou o metanol como agente de transesterificação para os três componentes.

$$
Y_{1}=96,78 x_{1}+96,14 x_{2}+97,3 x_{3}+0,96 x_{1} x_{2}+2,16 x_{1} x_{3}+0,68 x_{2} x_{3}-2,58 x_{1} x_{2} x_{3}
$$

A análise de variância mostrou que apenas os termos lineares foram significativos em nível de $5 \%$ e o teste de Tukey mostrou não haver diferença significativa, entre todos os tratamentos utilizados, no mesmo nível de significância, indicando que os três catalisadores utilizados apresentam efeito semelhante na reação de obtenção do biodiesel B100. Além disso, de acordo com o teste de Levene's, foi aceita a hipótese de homogeneidade da variância, em nível de $5 \%$, pois o valor do $\mathrm{p}$ foi de $81,89 \%$ (CALADO; MONTGOMERY, 2003)
A região de combinação ternária entre as variáveis independentes $\mathrm{x}_{1}, \mathrm{x}_{2}$ e $\mathrm{x}_{3}$ pode ser observada através das curvas de nível apresentadas na Figura 2. A figura mostra as regiões de contorno da superfície de resposta para a variável dependente, rendimento da reação, obtidas pelo modelo matemático, quando se utilizou o metanol. A Figura 2 mostra que o melhor rendimento pode ser obtido utilizando-se como catalisador uma mistura de hidróxido de sódio e metóxido de sódio.

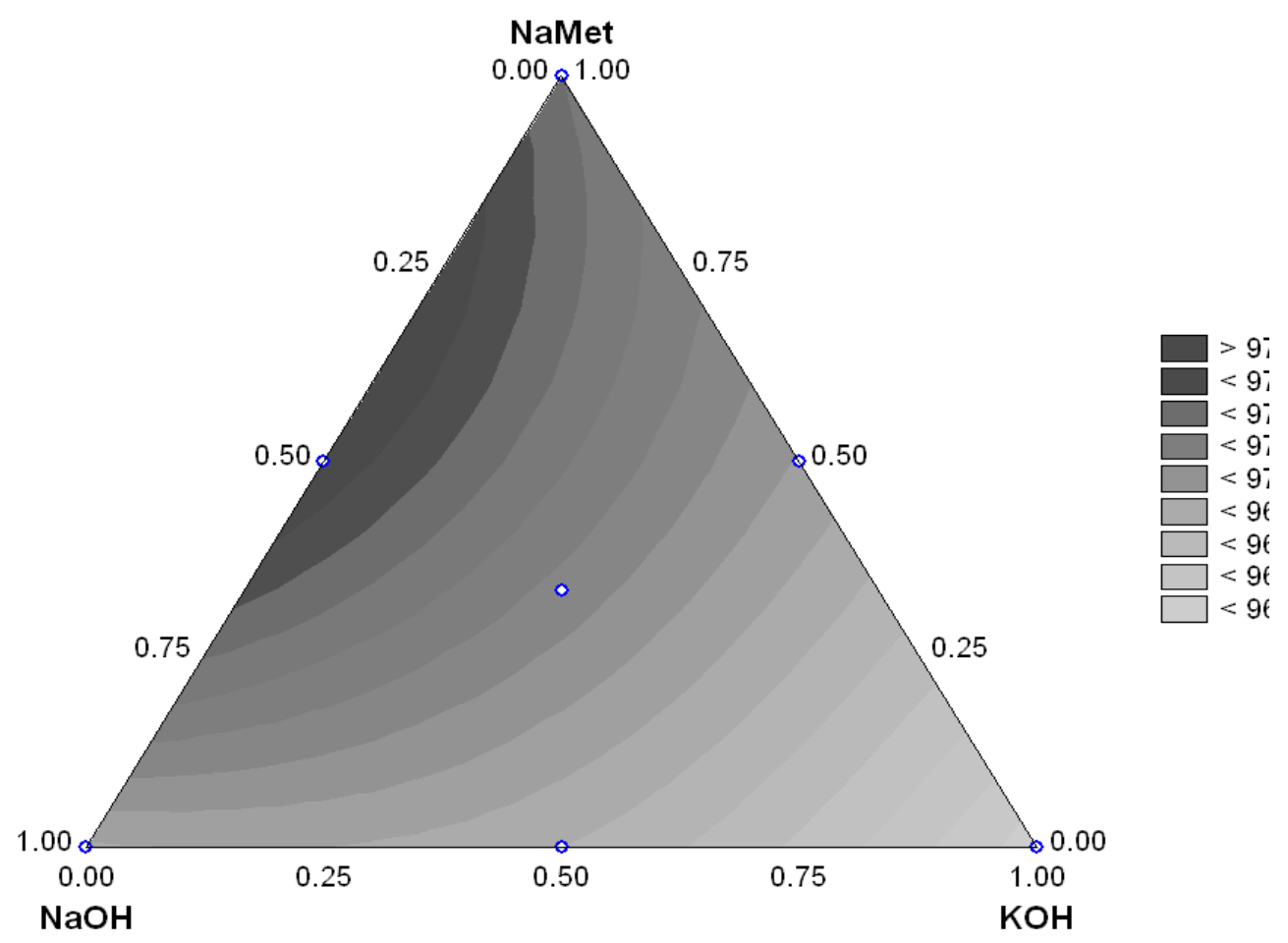

Figura 2. Região de contorno da resposta rendimento para a combinação ternária quando se utilizou o metanol na reação.

A otimização do rendimento da reação por meio da equação preditiva, está ilustrada na Figura 3. Ela mostra que um rendimento de $97,60 \%$ pode ser obtido quando se usa $30,77 \%$ de $\mathrm{NaOH}$ e $69,23 \%$ de metóxido de sódio. 

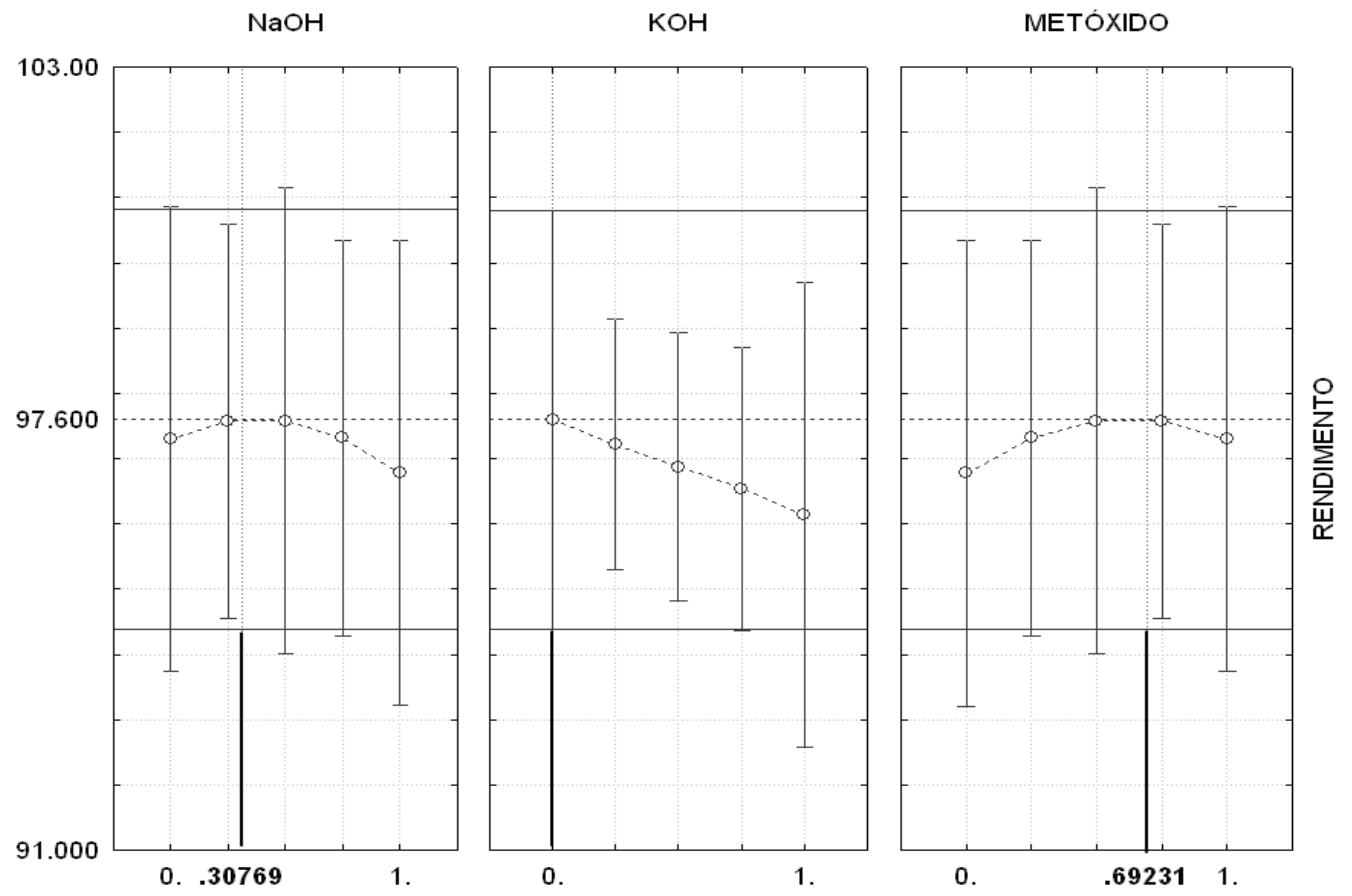

Figura 3. Gráfico das condições ótimas para as variáveis estudadas.

A reação de obtenção do biodiesel B100 utilizando as condições ótimas teve um rendimento de $97,15 \%$ validando com isso a equação preditiva obtida.
A Figura 4 mostra o cromatograma do biodiesel B100 obtido, utilizando-se as condições ótimas apresentadas na Figura 3.

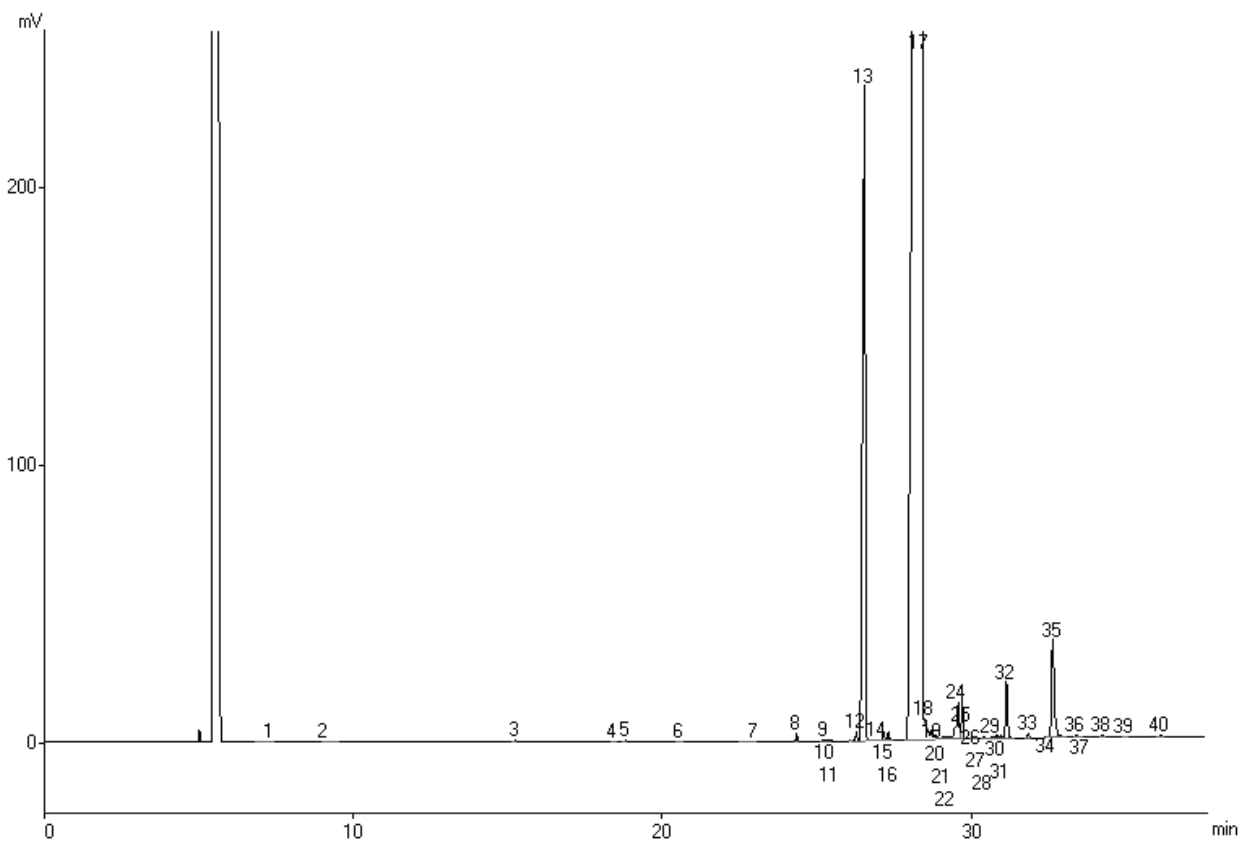

Figura 4. Perfil cromatográfico da amostra de Biodiesel B100 obtido nas condições ótimas. 
O teor de ésteres metílicos no biodiesel é um parâmetro previsto na norma EN 14214 e na RANP 07/08, cuja porcentagem mínima exigida de éster é de $96,5 \%$ massa, a ser determinada através do método cromatográfico EN ISO 14103. A norma brasileira recomenda ainda o uso do método ABNT NBR 15342, a ser empregado na análise de biodieseis oriundos de gordura animal ou de misturas de matérias primas distintas (LÔBO; FERREIRA; CRUZ, 2009).

A análise cromatográfica (Figura 4) mostra que o biodiesel obtido consiste basicamente dos ésteres metil palmítico, metil oleato, metil linoleato, metil linoleneato bem como outros metil éster cuja composição varia do $\mathrm{C} 8: 0$ até $\mathrm{C} 22: 0$. Os picos 3 a 9 correspondem aos ésteres com composição química variando de $\mathrm{C} 8$ a $\mathrm{C} 14$, respectivamente, representando $0,15 \%$ da amostra de biodiesel. O pico 13, com tempo de retenção de 27 minutos, representa o éster metílico do ácido graxo C16:0 na proporção de $12,16 \%$ e os picos com tempo de retenção ao redor de 29 minutos, representam juntos 83,23\%, sendo compostos pelos ésteres metílicos C18:0; C18:1 e C18:2. Os picos 24 a 30 correspondem aos ésteres C20 a C22 representando 1,22\% da amostra. Portanto, estes ésteres juntos somam 96,76\% das substâncias presentes no biodiesel B100 obtido estando, portanto, em acordo com a especificação da União Européia onde o teor de ácidos graxos livres, álcool, glicerina e água devem ser mínimos de modo que a pureza do biodiesel deve ser maior que 96,5\% (KARAOSMANOGLU; BECKER, 1996). O teor de glicerina livre observado foi de 2,2 $\mathrm{mg} / 100 \mathrm{~g}$ de amostra valor bastante inferior ao da legislação brasileira que prevê um teor máximo de glicerina livre de $0,02 \%(\mathrm{~m} / \mathrm{m})$ (BRASIL, 2008).

A determinação da glicerina residual serve como parâmetro para avaliar a eficiência do processo de purificação do biodiesel. Altas concentrações de glicerina no biodiesel provocam problemas de armazenamento, pois quando o biodiesel é misturado com o diesel de petróleo, observa-se a separação da glicerina nos tanques de estocagem. Problemas como formação de depósitos, entupimento dos bicos injetores do motor e emissões de aldeídos também estão relacionados com a alta concentração da glicerina no biodiesel (LÔBO; FERREIRA; CRUZ, 2009).

\section{Transesterificação com etanol}

A Tabela 2 mostra o delineamento simplexcentróide utilizado bem como os valores médios experimentais dos rendimentos obtidos em triplicata, com os diferentes catalisadores previamente dissolvidos no etanol em excesso. Após a separação da glicerina o biodiesel obtido foi lavado com água acidificada e desumidificado em estufa.

Tabela 2 - Delineamento experimental e o rendimento obtido quando se utilizou o etanol.

\begin{tabular}{cccccccc}
\hline $\begin{array}{c}\text { Delineamento } \\
*\end{array}$ & $(1 ; 0 ; 0)$ & $(0 ; 1 ; 0)$ & $(0 ; 0 ; 1)$ & $(1 / 2 ; 1 / 2 ; 0)$ & $(1 / 2 ; 0 ; 1 / 2)$ & $(0 ; 1 / 2 ; 1 / 2)$ & $(1 / 3 ; 1 / 3 ; 1 / 3)$ \\
$\begin{array}{c}\text { Rendimento } \\
(\%)\end{array}$ & 81,01 & 84,76 & 89,32 & 80,17 & 85,60 & 83,94 & 86,83 \\
\hline
\end{tabular}

$*(\% \mathrm{NaOH}, \% \mathrm{KOH}, \% \mathrm{NaEt})$

O domínio experimental consistiu de diferentes proporções dos catalisadores utilizados, variando de 0 a $100 \%$ sendo $x_{1}$ representado pelo hidróxido de sódio, $\mathrm{x}_{2}$ pelo hidróxido de potássio e $\mathrm{x}_{3}$ pelo etóxido de sódio. Na equação canônica (2), ajustada aos dados experimentais, $\mathrm{Y}_{2}$ representa o rendimento da reação quando se utilizou o etanol, como agente de transesterificação, para os três componentes. 


$$
Y_{2}=81,01 x_{1}+84,76 x_{2}+89,32 x_{3}-10,86 x_{1} x_{2}+1,74 x_{1} x_{3}-12,40 x_{2} x_{3}+113,07 x_{1} x_{2} x_{3}
$$

A análise de variância mostrou que apenas os termos lineares foram significativos em nível de $5 \%$ e o teste de Tukey mostrou não haver diferença significativa, entre todos os tratamentos, no mesmo nível de significância, indicando que os três catalisadores utilizados também aqui apresentam efeito semelhante na reação de obtenção do biodiesel B100. O teste de Levene's apresentou $\mathrm{p}=9,67 \%$ indicando que a hipótese de homogeneidade da variância pode ser aceita (CALADO; MONTGOMERY, 2003)
A região de combinação ternária entre as variáveis independentes $\mathrm{x}_{1}, \mathrm{x}_{2}$ e $\mathrm{x}_{3}$ pode ser observada através das curvas de nível apresentadas na Figura 5. A figura mostra as regiões de contorno da superfície de resposta para a variável dependente rendimento da reação, obtidas pelo modelo matemático, quando se utilizou o etanol. A Figura 5 mostra que o melhor rendimento situa-se entre os catalisadores hidróxido de sódio e etóxido de sódio.

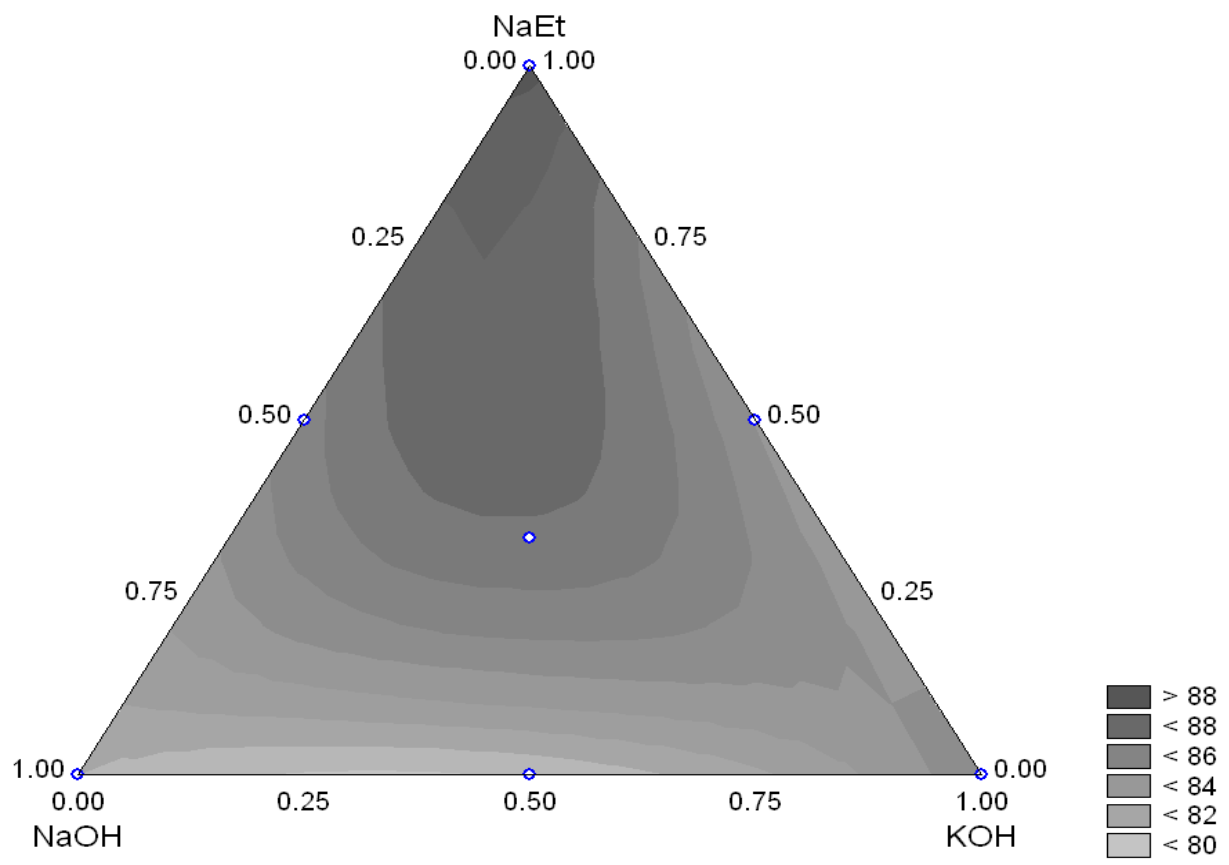

Figura 5. Região de contorno da resposta rendimento para a combinação ternária quando se utilizou o etanol na reação.

A otimização do rendimento da reação por meio da equação preditiva, está ilustrada na Figura 6. Ela mostra que um rendimento de $89,32 \%$ pode ser obtido quando se usa apenas o etóxido de sódio como catalisador. 


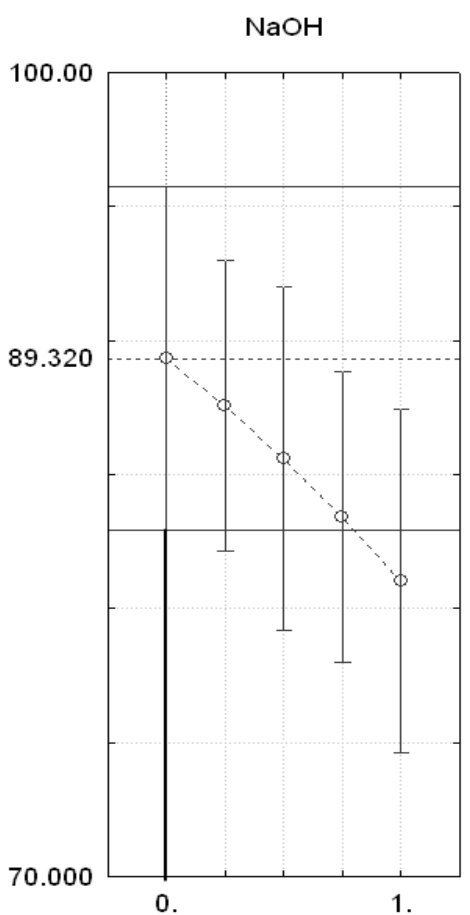

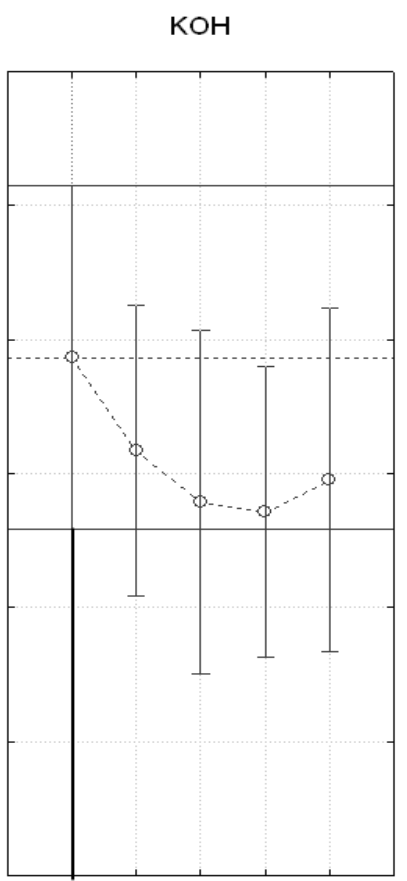

0 .

1.

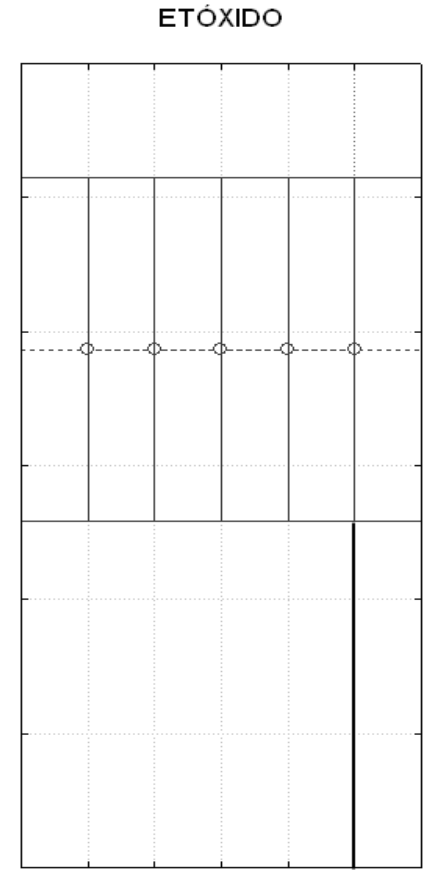

$\frac{\text { o }}{\text { 을 }}$

Figura 6. Gráfico das condições ótimas para as variáveis estudadas.

Areação de obtenção do biodiesel B100utilizando as condições ótimas fornecidas pela otimização teve um rendimento de $89,32 \%$ validando com isso a equação preditiva obtida.
A Figura 7 mostra o cromatograma do biodiesel B100 obtido, utilizando-se as condições ótimas apresentadas na Figura 6.

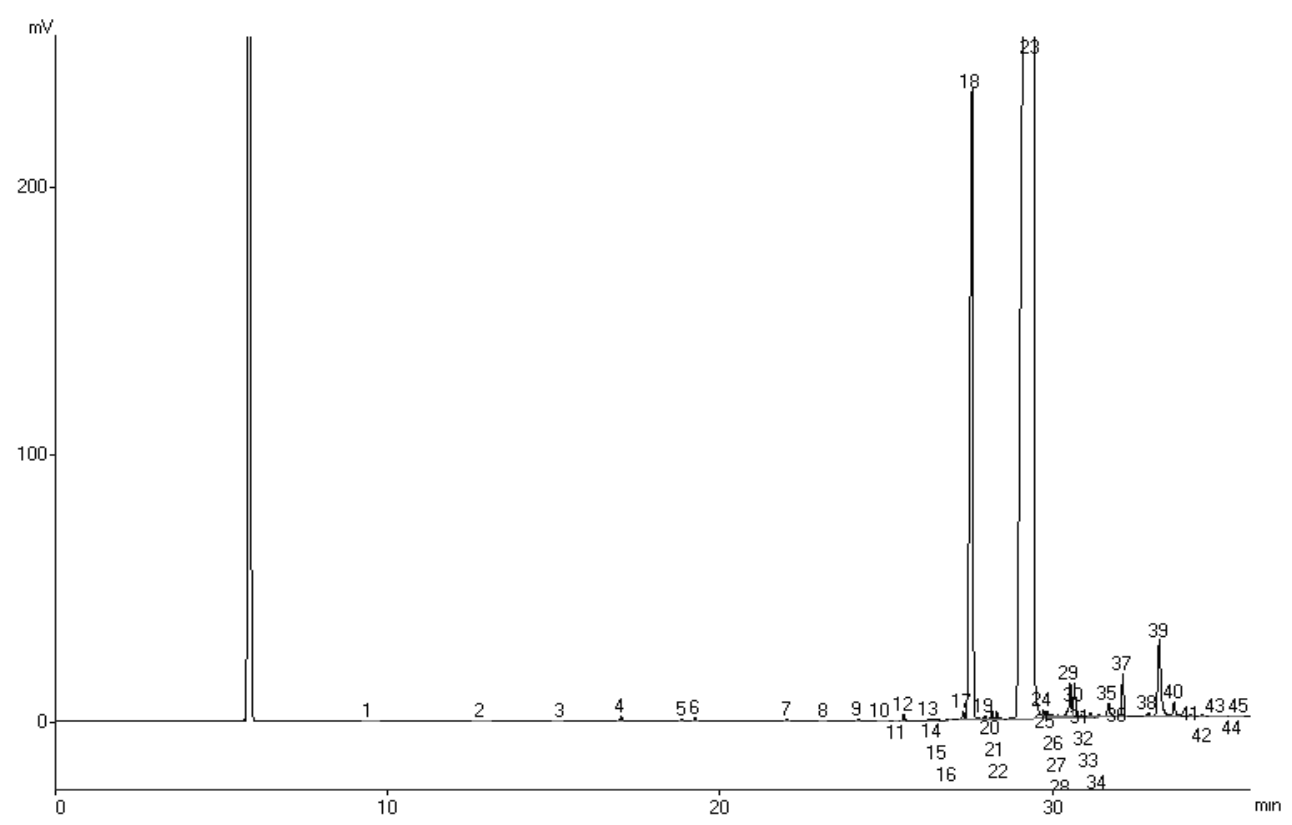

Figura 7. Perfil cromatográfico da amostra de Biodiesel B100 obtido nas condições ótimas. 
A análise cromatográfica mostra que o biodiesel obtidoconsistebasicamentedos ésteres etil palmítico, etil oleato, etil linoleato, etil linoleneato bem como outros etil ésteres cuja composição varia do C14:0 até C24:0. O pico (18) com tempo de retenção de 27 minutos, representa o éster metílico do ácido graxo C16:0 na proporção de $12,48 \%$ e os picos com tempo de retenção ao redor de 29 minutos, representam juntos $83,12 \%$, sendo compostos pelos ésteres etílicos C18:0; C18:1 e C18:2. Os demais ésteres obtidos, em menores concentrações somam 1,32\%
Portanto, estes ésteres juntos somam 96,92\% das substâncias presentes no biodiesel B100 obtido.

\section{Modelo combinado}

O modelo combinado a seguir foi desenvolvido conforme proposta de Cornell (1990) onde o ensaio realizado com o metanol foi codificado para $\mathrm{z}=+1$ e aquele realizado com etanol foi codificado para $\mathrm{z}$ $=-1$.

$$
\begin{aligned}
& Y_{3}=88,895 x_{1}+7,885 x_{1} z+90,45 x_{2}+5,69 x_{2} z+93,31 x_{3}+3,99 x_{3} z-4,95 x_{1} x_{2} \\
& +5,91 x_{1} x_{2} z+1,95 x_{1} x_{3}+0,21 x_{1} x_{3} z-5,86 x_{2} x_{3}+6,54 x_{2} x_{3} z+55,335 x_{1} x_{2} x_{3} \\
& -57,825 x_{1} x_{2} x_{3} z
\end{aligned}
$$

O teste de Tukey e o de Levene's mostraram diferença significativa, em nível de $5 \%$, entre os ensaios realizados com metanol e etanol.

A análise da equação mostra que os menores rendimentos são obtidos quando se utiliza o etanol como agente de transesterificação, isto é, com $\mathrm{z}=-1$. O menor rendimento, quando comparado com a reação de transesterificação com metanol, deve-se ao fato do etanol promover uma maior dispersão da glicerina e dos monoésteres presentes no biodiesel, dificultando a separação das fases. Isto representa, industrialmente, maiores custos na etapa de purificação ocasionando maiores perdas e, com isso, um menor rendimento no processo. Porém, o etanol é menos tóxico, renovável e produz biodiesel com maior número de cetano e lubricidade (LÔBO; FERREIRA; CRUZ, 2009).

Aplicando-se na equação conjunta os valores otimizados da concentração dos catalisadores (Figuras 3 e 6), obtiveram-se os mesmos valores dos rendimentos, isto é, 97,61\% e 89,32\% quando se utilizou o metanol e etanol respectivamente mostrando que a equação, que inclui a variável discreta, pode ser utilizada para fins preditivos.

\section{Conclusão}

Através dos resultados obtidos podemos concluir que a rota etílica, na produção de biodiesel, não apresentou diferença significativa entre os seus tratamentos, mas quando comparada com a rota metílica, ela se mostra inferior quanto ao rendimento da reação. Da mesma forma que a rota etílica, a rota metílica não apresentou diferença significativa entre os seus diferentes tratamentos.

As duas rotas utilizadas produzem biodiesel B100 dentro das especificações estabelecidas pela Legislação Brasileira.

O delineamento de mistura simplex-centróide mostrou ser uma boa ferramenta para avaliar a eficiência de catalisadores ou a mistura destes na otimização do rendimento da reação de transesterificação de óleo de soja refinado.

\section{Referências}

ARTEAGA, G.E.; LI-CHAN,E.;VAZQUEZ-ARTEAGA, M. C.; NAKAI, S. Systematic experimental designs for product formula optimization. (Review). Trends in Food Science \& technology, Cambridge, v. 5, n. 8, p. 243-253, 1994. 
BRASIL. Resolução n ${ }^{\circ}$, de 19 de março de 2008 da ANP, Agência Nacional do Petróleo, Gás Natural e Biocombustiveis. Estabelece a especificação para a comercialização de biodiesel que poderá ser adicionado ao óleo diesel. Diário Oficial da União, Brasília, 20 de março de 2008.

CALADO, V.; MONTGOMERY, D. Planejamento de experimentos usando o Statistica. Rio de Janeiro: E-Papers Serviços Editoriais, 2003.

CHEN, J. S.; LEE, C. M.; CRAPO, C. Linear programming and response surface methodology to optimize surini gel texture. Journal of food Science, Chicago, v. 58, n. 3, p. 535-538, 1993.

CORNELL, J. A. Experiments with mixtures - designs, models and the analysis of mixture data. 2. ed. New York: John Wiley and Sons, 1990.

DANTAS, T. N. C.; SILVA, A. C.; NETO, A. A. D. New microemulsion systems using diesel and vegetables oils. Fuel, London, v. 80, n. 1, p. 75-81, 2001.

DERRINGER, G.; SUICH, R. Simultaneous optimization of several response variables. Journal of Quality technology, Milwaukee, v. 12, n. 4, p. 214-219, 1980.

FUKUDA, H.; KONDO, A.; NODA, H. Biodiesel fuel production by transesterification of oils. Journal of Bioscience and Bioengineering, Osaka, v. 92, n. 5, p. 405-416, 2001.
GACULA, M. C. Design and analysis of sensory optimization. Trumbull: Food \& Nutrition Press, 1993.

HOLANDA, A. Biodiesel e inclusão social. Brasília: Câmara dos Deputados, 2004.

KARAOSMANOGLU, F.; BECKER, U. G. Used oil as a fuel oil alternative. Energy Sources, New York, v. 18, n. 6, p. 637-644, 1996.

LÔBO, I. P.; FERREIRA, S. L. C.; CRUZ, R. S. Biodiesel: parâmetros de qualidade e métodos analíticos. Quimica Nova, São Paulo, v. 32, n. 6, p. 1596-1608, 2009.

McLEAN, R. A.; ANDERSON, V. L. Extreme vertices designs of mixture experiments. Technometrics, Washington, v. 8, n. 3, p. 447-454, 1966.

STATISTICA. Graphics software. Tulsa: Statistica For Windows, 2009. v. 9.

STEINBERG, M. D., HUNTER W. G. Experimental design: review and comment. Technometrics, Washington, v. 26, n. 2, p. 71-130, 1984.

THONSON, D. R. Designing mixture experiments - A review. Transactions of the Assae, St.Joseph, v. 24, n. 4, p. 1077-1086, 1981.

Recebido em 12 Janeiro, 2010 - Received on January 12, 2010. Aceito em 23 Março, 2010 - Accepted on March 23, 2010. 